\title{
Optimized Solutions for Thermal and Visual Comfort in the Design of a Nearly Zero-Energy Building
}

\author{
Giovanna De Luca, Ilaria Ballarini, Argun Paragamyan, Anna Pellegrino, Vincenzo Corrado \\ Politecnico di Torino, Department of Energy, Torino, Italy
}

\begin{abstract}
Alongside the importance of increasing the building energy performance, the indoor environmental quality has to be considered as a part of the total building performance. The research aims to reduce the imbalance between the visual and thermal domains through the optimization of different design parameters in compliance with the nZEB requirements. Different energy efficiency actions (different insulation materials, glazing solutions and control strategies of the solar shading devices) were applied on an existing office building. The analysis shows the possibility to design the refurbishment of an existing building into a nZEB while ensuring visual and thermal comfort.
\end{abstract}

\section{Introduction}

The energy performance improvement of existing buildings is promoted by Directive 2010/31/EU, which enforces the Member States to draw up national plans for increasing the refurbishment of existing buildings into nearly zero-energy buildings (nZEBs) (European Commission, 2010). Alongside the importance of increasing the building energy performance, the indoor environmental quality (IEQ) has to be considered as a part of the total building performance, although ensuring the compliance with comfort requirements within a refurbishment scenario it is not a commonplace task.

Many studies demonstrated the negative effect of energy efficiency measures on the visual comfort related to a reduction of daylight availability; these actions mainly concerned windows replacement, solar shading devices installation, and the reduction of the window carcass due to the thickening of the thermal insulation. Reinhart (2002) and Mainini et al. (2015) investigated the influence of glazing visible transmittance on the lighting energy consumption in the envelope refurbishment of office buildings, both showing an increase in primary energy use for lighting. On the other hand, also dynamic glazing and smart-windows may lead to an imbalance between thermal and visual performance, as stated by Dussault et al. (2017) and Ajajja and Andréa (2015). David et al. (2011) highlighted the lack of a process to design the shading devices that takes into account both thermal and visual issues, and proposed simple indexes to compare the thermal and visual efficacy of different types of solar shadings. In the same way, different solar shading configurations were tested by Hernandez et al.
(2017); a significant lowering in visual comfort, by applying specific louvre angles in order to maximises the cooling energy performance in an office building were highlighted. Many studies focused on the effect of different window-to-wall ratio $(W W R)$ on both visual and thermal performance, such as Pellegrino et al. (2017) and Xue et al. (2019); they showed an increase of the building overall energy demand by decreasing of indoor daylight availability, or optimised the $W W R$ and the sunshades operation to meet the daylighting standard.

The "Renovation of existing buildings in nZEB vision (nearly Zero Energy Buildings)" Project of National Interest (PRIN 2015), funded by the Italian Ministry of Education, Universities and Research (MIUR), aims at studying solutions for the transformation of existing buildings into nZEBs, considering both technical and economic implications. A specific line of research aims at investigating the best trade-off between thermal and visual parameters for the nZEB design.

Major building renovations, including retrofit actions both on building envelope and on technical building systems, have not been widely investigated yet. Thus, it is of crucial importance to build-up an approach that allows to evaluate the IEQ implication of major refurbishment scenarios on the existing building stock, considering different type of thermal and visual comfort evaluations. Through this in-depth approach, the design of nearly-zero energy buildings, regardless of whether they are new or existing buildings undergoing refurbishment, can address the optimization of the overall building performance, identifying the best tradeoff between indoor environmental quality (IEQ) and the compliance with the nZEB requirements.

The analysis presented in this article starts from the findings of a previous work (Ballarini et al., 2019), in which the impact on the visual and thermal comfort of the energy refurbishment measures as to comply with the nZEB requirements were assessed for an existing office building. The results of the previous analysis on a representative building storey showed a consistent imbalance both between the thermal and visual comfort, and between the thermal comfort related to two different orientations. In fact, on one hand, the hyper insulated envelope assures a high thermal comfort condition in the North-oriented offices, while the un-efficient solar shading devices operation deals to a lower thermal 
comfort level in the South-oriented offices, though guaranteeing an overall acceptable thermal comfort condition. On the other hand, the reduced glazed surface, the low-transmittance glazing and the external obstructions due to the consistent thickness of the external insulation lead to not acceptable values as regards the visual comfort indexes, both in the Northand South-oriented offices.

From these findings, different retrofit solutions on the opaque and transparent envelope and optimised operation of the solar shading devices are combined and tested in the present work, as to identify the best combination to enhance daylighting and visual comfort. Each combination was evaluated in terms of thermal and visual comfort indexes, energy performance and compliance with the nearly zero-energy building requirements.

\section{Methodology}

The methodology applied in the present work includes thermal and visual comfort evaluations and energy performance assessments. All the considered aspects were evaluated through numerical simulations, performed with the EnergyPlus and Diva4Rhino dynamic simulation tools, for thermal and visual performance respectively. The performance indexes were calculated according to international technical standards and international references, as described in the following paragraphs.

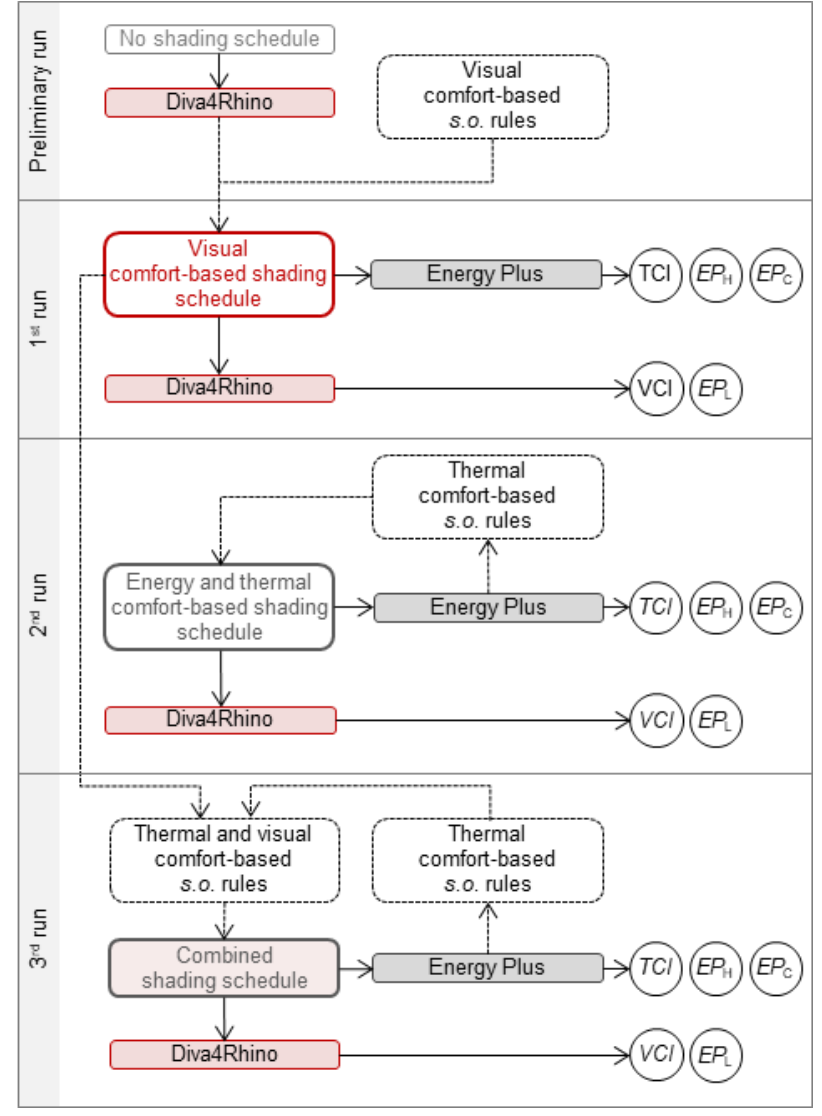

Figure 1: Methodology flow-chart.

The procedure includes three main phases, corresponding to as many theoretical shading control rules, as shown in Figure 1. The first phase consists in a preliminary simulation performed as to assess and to apply a set of visual comfort-based rules to determine the optimised visual comfort shading operation (s.o. in Figure 1). In the second phase, a control loop is implemented in EnergyPlus as to define the thermal comfort-based shading operation. Finally, the third phase is aimed at identifying a combined shading control strategy for both visual and thermal comfort; for this purpose, the shading control loop defined in the previous phase is implemented with the visual comfort-based shading operation. The proposed methodology is applied to a set of combination of energy efficiency measures on the opaque and transparent envelope. The results of each phase are the definition of hourly shading operation schedules, then implemented in the simulation software for the visual and thermal comfort indexes calculation (respectively $V C I$ and $T C I$ in Figure 1), and for the energy performance assessment for space heating, space cooling and lighting (respectively $E P_{\mathrm{H}}, E P_{\mathrm{C}}$ and $E P_{\mathrm{L}}$ in Figure 1).

\section{Thermal and visual comfort evaluation}

The thermal comfort was evaluated as specified by the EN 16798-1 technical standard (European Committee for Standardization, 2019) and was referred to specific periods belonging neither to the heating nor to the cooling season. The thermal comfort during the heating and cooling seasons was assumed to be achieved with the mechanical heating and cooling systems. For mid seasons, the so-called adaptive criteria were applied and evaluated with respect to a medium comfort level (category II). Following the adaptive criteria approach, the hourly comfort operative temperature varies in function of the running mean outdoor temperature, which is defined as an exponentially weighted running mean of the outdoor air temperature.

Thermal comfort was assessed by means of the weighted hours of discomfort (WHD) index, which expresses the time (in hours) during which the indoor operative temperature exceeds a specific range during the occupancy hours, weighted by a factor that is a function of the temperature deviation out of the range. The considered range is defined as a variation of the optimal comfort operative temperature of $+3{ }^{\circ} \mathrm{C}$ (highest limit) and $-4{ }^{\circ} \mathrm{C}$ (lowest limit). In the index determination, cold discomfort $\left(W H D_{\mathrm{c}}\right)$ and warm discomfort $\left(W H D_{\mathrm{w}}\right)$ were evaluated separately, according to the EN ISO 7730 technical standard specifications (European Committee for Standardization, 2005). The WHD indexes were calculated from hourly values of indoor operative temperature derived from simulations carried out through Energy Plus.

The analysed period for the thermal comfort indexes assessment was defined in a previous work (Ballarini et al., 2019) on the basis of an analysis of the number of free-floating hours. Excluding the heating period fixed by the Italian legislation (e.g. for the considered climatic zone, from October $15^{\text {th }}$ to April $\left.15^{\text {th }}\right)$, the thermal comfort analysis were carried out in the period from 
April $16^{\text {th }}$ to May $31^{\text {st }}$ and from September $1^{\text {st }}$ to October $14^{\text {th }}$.

The visual comfort analysis referred to daylighting has been carried out taking into account two different aspects: the daylight supply, which is both related to visual performance and indicative of the energy performance for lighting, and the daylight glare probability $(D G P)$. When daylighting is not sufficient, it is assumed that the electric lighting system integrates or replaces daylight in order to guarantee visual comfort and target illuminance.

To estimate the indoor daylight availability the spatial daylight autonomy ( $s D A)$ has been calculated. This metric is based on the criteria that a space is considered to have adequate daylight if a target illuminance is achieved across a fraction of space for a fraction of time. The metric, first adopted by the Illuminating Engineering Society (IES) in the Report LM-83-12 (IES Daylight Metrics Committee, 2012) has been recently introduced in the European Standard EN 17037:2018 to assess the Daylight Provision in interior spaces (European Committee for Standardization, 2018). In this study, the Daylight Provision was calculated following the method provided by the EN 17037 standard. The hourly illuminances calculated through the climate-based simulation on the horizontal plane $(\mathrm{h}=0,85 \mathrm{~m})$ were elaborated to determine the fraction of space that meets the recommended target illuminance (500 lux) for at least $50 \%$ of time $\left(s D A_{500,50 \%}\right)$. According to the standard recommendations, the calculated fraction of space should be at least $50 \%$. To assess visual comfort in terms of glare, the $D G P$ has been calculated for a reference observer's position, assuming a viewing direction towards the façade, with a viewing angle of $45^{\circ}$ (see Figure 2). The annual DGP profile has been elaborated to obtain the fraction of time of the occupied hours for which the DGP exceeded a defined threshold $\left(F_{D G P \text {,exceeded }}\right)$. The threshold assumed is $40 \%$, and to achieve a medium glare protection, according to the standard EN 17037, the maximum value of $F_{D G P \text {,exceeded }}$ should be $5 \%$.

\section{Energy performance assessment}

The building overall energy performance $(E P)$ was assessed according to the EN ISO 52000-1 technical standard (European Committee for Standardization, 2017) and was expressed in terms of annual overall nonrenewable primary energy normalised by the conditioned net floor area. The energy services considered in the EP calculation include space heating, cooling and lighting. The electricity production from photovoltaic system was allocated to the different energy services proportionally to the electricity demand of each service. The energy performance was assessed through dynamic simulations using the Energy Plus software, while the lighting analysis was carried out with the DIVA4Rhino software. The compliance with the nZEB requirements was assessed for each combination of energy efficiency measures by means of the reference building approach as specified by the Italian legislation (Italian Republic, 2015).

\section{Case study}

\section{Description of the building}

The case study is an existing office building sited in Torino (northern Italy), composed of seven above ground North-South oriented stories. The presented methodology was referred to a representative building storey. In fact, the fifth storey above ground (Figure 2) represents an average condition while concerning the shadings provided by the external surrounding obstructions; thus, the results of the comfort and energy performance evaluations are not influenced by too favourable or unfavourable conditions. The representative building storey is composed of nine South- and five North-oriented office modules, separated by unoccupied areas. Each office module is characterised by a net conditioned floor area of $17,3 \mathrm{~m}^{2}$, an internal height of $2,7 \mathrm{~m}$, and two windows. As regards the solar shading devices, external blinds are installed on the South-oriented windows, while the North-oriented windows are not provided with any shading system. The storey was divided into three thermal zones (North-oriented offices, South-oriented offices and unoccupied areas respectively); it was assumed to be surrounded by identical storeys (for both geometry and users' behaviour), thus horizontal internal partitions were modelled as adiabatic components.

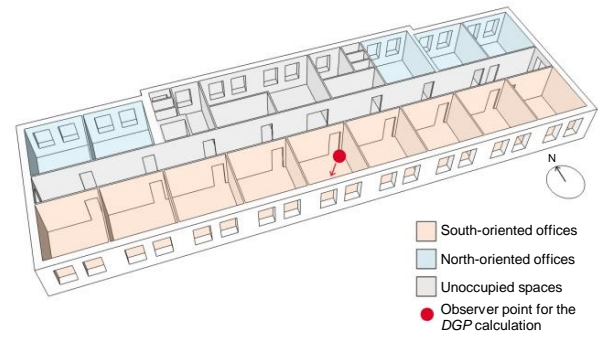

Figure 2: Analysed building storey.

A standardised user behaviour, both regarding occupancy, heat gains and natural ventilation, was considered in each combination. The scheduled hourly values were derived from the EN 16798-1 technical standard. The storey was adopted to be served by a heating, a cooling and a lighting system. An ideal HVAC system, modelled as a Variable Air Volume terminal unit, which varies the supply air flow rate in order to satisfy the zone heating and cooling loads, was considered to evaluate the heating and cooling energy performance of the building storey. An air-to-water heat pump was considered as the heating and cooling generator. Reference mean seasonal generator efficiency and utilization subsystems efficiency ( $\eta_{\mathrm{u}}$ equal to 0,81 , referred to heat emission, control and distribution) were used (Italian Republic, 2015). As regards the lighting system, a daylight responsive control was considered for the lighting energy performance assessment. The parameters for the energy calculation regarding users' behaviour and technical building systems are reported in Table 1. 
Table 1: Parameters used for energy simulations.

\begin{tabular}{|c|c|}
\hline Parameter & Value \\
\hline $\begin{array}{c}\text { Occupancy: } \\
\text { Schedule (EN 16798-1) } \\
\text { Occupancy density }\end{array}$ & $\begin{array}{l}8 \text { a.m. }-5 \text { p.m. } \\
0,07 \text { persons } \mathrm{m}^{-2}\end{array}$ \\
\hline $\begin{array}{c}\text { Appliances: } \\
\text { Schedule (EN 16798-1) } \\
\text { Appliance loads }\end{array}$ & $\begin{array}{l}8 \text { a.m. }-5 \text { p.m. } \\
12 \mathrm{~W} \mathrm{~m}^{-2}\end{array}$ \\
\hline $\begin{array}{c}\text { Natural ventilation: } \\
\text { Air changes (occupied hours) } \\
\text { Infiltration air changes }\end{array}$ & $\begin{array}{c}0,85 \mathrm{~h}^{-1} \\
0,2 \mathrm{~h}^{-1}\end{array}$ \\
\hline $\begin{array}{c}\text { Heating system: } \\
\text { Availability } \\
\text { Daily operation } \\
\text { Operative temperature set-point } \\
\text { Mean seasonal generator efficiency }\end{array}$ & $\begin{array}{c}\text { October } 15^{\text {th }}-\text { April } 15^{\text {th }} \\
8 \text { a.m. }-5 \text { p.m. } \\
20^{\circ} \mathrm{C} \\
3,00\end{array}$ \\
\hline $\begin{array}{c}\text { Cooling system: } \\
\text { Availability } \\
\text { Daily operation } \\
\text { Operative temperature set-point } \\
\text { Mean seasonal generator efficiency }\end{array}$ & $\begin{array}{c}\text { June } 1^{\text {st }}-\text { August } 31^{\text {st }} \\
8 \text { a.m. }-5 \text { p.m. } \\
26^{\circ} \mathrm{C} \\
2,50\end{array}$ \\
\hline $\begin{array}{c}\text { Lighting system: } \\
\text { Lighting Power Density }(L P D)\end{array}$ & $7 \mathrm{~W} \mathrm{~m}^{-2}$ \\
\hline $\begin{array}{c}\text { Photovoltaic system: } \\
\text { Peak power }\end{array}$ & $2,3 \mathrm{~kW}$ \\
\hline
\end{tabular}

Energy performance and daylighting evaluations were carried out through annual climate-based simulation using the International Weather for Energy Calculations (IWEC) data file for the city of Torino.

\section{Energy efficiency measures}

The tested energy efficiency measures include three solutions on the opaque envelope, two on the transparent envelope and three regarding the shading solar systems. In the present work, all the possible combination between these energy efficiency measures were tested (18 combinations).

Regarding the opaque envelope, three thermal insulation solutions were tested; in particular, the first solution (INS1), consisting of $14 \mathrm{~cm}$ of EPS external insulation, is the energy efficiency solution selected within a previous research (Corrado et al., 2017) to achieve both the nZEB requirements fixed by Italian legislation (Italian Republic, 2015) and the lowest global cost in 30 years building lifetime. The second solution (INS2) consists of $3 \mathrm{~cm}$ of a high-performance insulation material (VIPs - vacuum insulation panels) on the external side of the wall, designed as to achieve the same thermal transmittance as the first solution while guaranteeing, at the same time, a less obstructed window surface area. As regards the third solution (INS3), an ingap insulation made of $12 \mathrm{~cm}$ of EPS was designed to take advantages of the existing un-insulated air gap. To avoid thermal bridges, the thermal insulation was designed also to cover the top and the lateral parts of the external window carcass. Therefore, for each solution, different window dimensions were considered to evaluate the effective net glazed area and external obstructions. The properties and characteristics of each solution are reported in Table 2.
Table 2: EEM - opaque envelope.

\begin{tabular}{|c|c|c|c|c|}
\hline ID & $\begin{array}{c}\text { Insulation } \\
\text { position and } \\
\text { thickness } \\
\text { [cm] }\end{array}$ & $\mathbf{U}_{\mathbf{o p}}\left[\mathbf{W ~ m ~}^{-\mathbf{2}} \mathbf{K}^{-\mathbf{1}}\right]$ & $\begin{array}{c}\text { Wall } \\
\text { thickness } \\
{[\mathbf{c m}]}\end{array}$ & $\begin{array}{c}\text { Window } \\
\text { area } \\
{\left[\mathbf{m}^{\mathbf{2}}\right]}\end{array}$ \\
\hline INS1 & External - 14 & 0,20 & 60 & 1,5 \\
\hline INS2 & External - 3 & 0,20 & 49 & 1,6 \\
\hline INS3 & In gap - 12 & 0,29 & 44 & 1,8 \\
\hline
\end{tabular}

Regarding the energy efficiency measures on the transparent envelope, different solutions were considered both for the windows and for the solar shading devices. About the windows, a double low-e glazing was combined with two frame solutions; WIN1 consists in an $8 \mathrm{~cm}$ of thickness PVC frame, while WIN2 is characterised by a PVC frame of $5 \mathrm{~cm}$. As regard the solar shading devices, the same technology was considered with three theoretical hourly-based shading control strategies: an energy and thermal comfort-based strategies (SHA1), a visual comfort-based rule (SHA2) and a last control strategy which combines the visual and thermal comfort rules (SHA3). The properties and characteristics of the energy efficiency measures on the transparent envelope are reported in Table 3.a and in Table 3.b, while the three shading control strategies are presented in Figure 3.

Table 3.a: EEM - transparent envelope.

\begin{tabular}{|c|c|c|c|c|c|}
\hline ID & $\begin{array}{c}\text { Glazing } \\
\text { type }\end{array}$ & $\begin{array}{c}\text { Frame } \\
\text { material } \\
\text { and } \\
\text { dimension } \\
{[\mathbf{c m}]}\end{array}$ & $\begin{array}{c}\mathbf{U}_{\mathbf{w}} \\
{\left[\mathbf{W ~ m}^{-2} \mathbf{K}^{-1}\right]}\end{array}$ & $\begin{array}{c}\mathbf{g}_{\mathbf{g l}} \\
(\mathbf{S H G C})\end{array}$ & $\begin{array}{c}\tau_{\text {vis }} \\
{[-]}\end{array}$ \\
\hline WIN1 & Double & PVC -8 & \multirow{2}{*}{1,7} & 0,67 & 0,8 \\
\hline WIN2 & Double & PVC -5 & & 0,6 & \\
\hline
\end{tabular}

Table 3.b: EEM - transparent envelope.

\begin{tabular}{|c|c|c|c|c|c|}
\hline ID & Position & $\begin{array}{c}\text { Control } \\
\text { rule }\end{array}$ & $\begin{array}{c}\tau_{\text {sol }} \\
{[-]}\end{array}$ & $\begin{array}{c}\mathbf{g}_{\text {gl } 1+s h} \\
(\text { SHGC) }\end{array}$ & $\begin{array}{c}\tau_{\text {vis }} \\
{[-]}\end{array}$ \\
\hline SHA1 & External & Thermal & \multirow{2}{*}{0,20} & 0,17 & 0,25 \\
\cline { 1 - 2 } SHA2 & External & Visual & \multirow{2}{*}{0,20} & & \\
\hline SHA3 & External & Combined & &
\end{tabular}

\section{Shading device control strategies}

Three shading device control strategies were considered in the present study. The energy and thermal comfortbased control rule is aimed at enhancing thermal comfort while improving the energy performance for heating and cooling. For this purpose, an EnergyPlus energy management system (EMS) program was designed as to perform three season-based control rules. During the heating season, as to maximise the solar heat gains, the solar shadings are always switched off. For the mid seasons, the control rule depends on the day of the week, the occupancy (occ in Figure 3), the incident global solar radiation on the South-oriented windows $\left(I_{\mathrm{s}, \mathrm{g}}\right)$, but it is strictly built upon the indoor operative temperature $\left(\theta_{\mathrm{o}}\right)$ and the optimal comfort operative temperature $\left(\theta_{\mathrm{c}}\right)$. Whenever the $I_{\mathrm{s}, \mathrm{gl}}$ exceeds the threshold value during the occupancy hours of the weekdays, the solar shading devices are switched on or off if the $\theta_{\mathrm{o}}$ oversteps the upper or lower value of the comfort operative 
temperature dead band (defined as $\theta_{\mathrm{c}} \pm 1$ ) respectively. On the other hand, the control rule for the weekends of both the mid and the cooling season only depends on the presence of solar radiation.
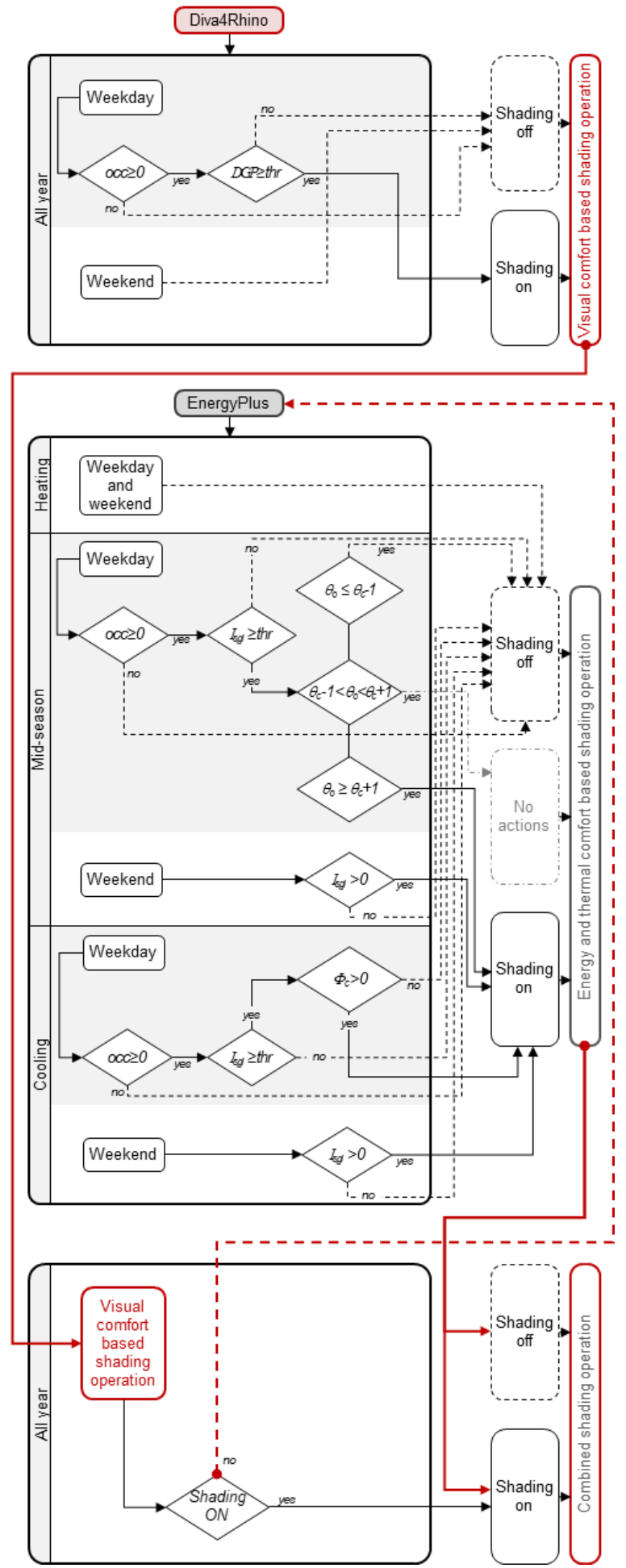

Figure 3: Shading devices control strategies.

Moreover, the visual comfort-based algorithm for the solar shading devices operation is aimed at improving the visual comfort conditions by reducing the discomfort glare occurrence. It works according to the Lightswitch algorithm (Reinhart, 2004) and it was designed to switch on the dynamic shading devices during the occupancy hours whenever the daylight glare probability $(D G P)$ exceeds the threshold value, equal to $40 \%$. Finally, the third rule combines the aforementioned rules by giving priority to the visual comfort-based control strategy. In fact, the thermal comfort-based control strategy unfolds for each time step in which SHA2 switches off the shading devices.

\section{Results and discussions}

The effects of the tested combinations of energy efficiency measures on the building envelope are presented as follow. Regarding the thermal performance, for each combination tested, cold thermal discomfort never occurs; due to the high levels of thermal insulation, the indoor operative temperature in the analysed period never exceeds the lower limit of the comfort temperature range. On the other hand, the hyper-insulation of the external walls does not allow the discharge of the accumulated heat, thus leading to an increase of thermal discomfort linked to the high indoor operative temperatures $\left(W H D_{\mathrm{w}}\right)$, which mainly occur in the second part of the free-floating period (from September $1^{\text {st }}$ to October $15^{\text {th }}$ ).

With regard to the visual comfort analysis, the Daylight Provision ranges from $27 \%$ to $77 \%$ for the South-facing offices and from $23 \%$ to $51 \%$ for the North-oriented offices. On the other hand, the $F_{D G P \text {,exceeded }}$ is $0 \%$ for the North side of the storey and ranges from $2,1 \%$ to $22,1 \%$ for the South orientation. The recommended values of $s D A_{500,50 \%}$ are respected for 11 configurations on 18: the INS3 configurations for the North- and South-oriented offices, the configurations with INS2-WIN2 and the INS2-WIN1-SHA2 on the South side. On the other hand, the $F_{D G P \text {,exceeded }}$ for South-oriented offices is never respected for the INS3 configurations and for the thermal comfort based shading.

Although the comfort analysis was performed separately for the North- and the South-oriented offices, the following analyses are focused on the South-oriented offices, since they show more representative results.

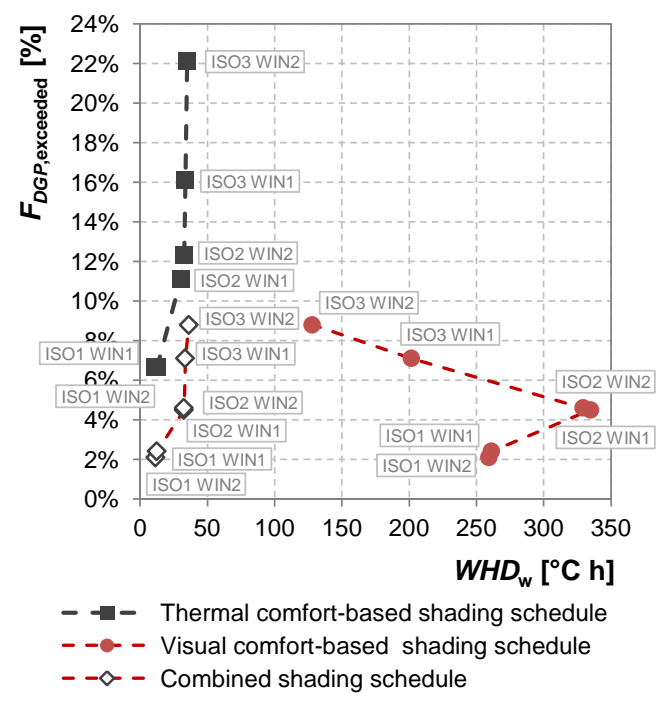

Figure 4: $F_{D G P \text { exceeded }}$ and $W H D_{\mathrm{w}}$ indexes for the tested combination of EEMs - South-oriented offices. 
Figure 4 shows the correlation between the $F_{\mathrm{DGP}}$,exceeded and the $W H D_{\mathrm{w}}$ indexes of the tested combination for the South-oriented offices. The graph highlights the strong influence of the solar shading devices control strategies on both the visual and the thermal performance. The thermal-comfort based control strategy shows an inverse relationship between the discomfort conditions and the external walls thickness; in fact, by implementing the solution characterised by the thinnest walls (INS3, ingap insulation), the less obstructed windows lead to higher indoor operative temperatures (and thermal discomfort values). Nevertheless, this shading control strategy leads to the lowest discomfort values among all the tested combinations (in a range from 12 to $35^{\circ} \mathrm{C} \mathrm{h}$ ). On the other hand, the worst results as regards the $F_{D G P \text {,exceeded }}$ discomfort $(22,1 \%$ for the INS3-WIN2SHA1 solution) take place by implementing the SHA1 control rule, since it is designed to switch off the shading devices during the winter seasons, when glare discomfort occurs more frequently (due to the height of the sun). Moreover, the combined shading schedule shows the same trend of the SHA1 operation, except for the $F_{D G P \text {,exceeded }}$ values decrease. Moreover, it is of crucial importance to highlight that the combined shading operation leads to the same results as regard the thermal comfort performance, due to the complementary operation of the SHA1 and SHA2 schedules. In fact, since the visual comfort-based schedules works mainly in the winter season, it has no influence on the thermal comfort condition, because the SHA1 enfolds in the periods analysed in the thermal comfort assessment. On the other hand, the visual comfort-based solar shading operation shows a different trend mainly as regard the thermal comfort conditions. The higher solar heat gains (due to the inactivated shading devices in the mid- and summer seasons) and the unfeasibility of the building envelope to discharge the accumulated heat leads to an increase of the operative temperatures, which exceeds the comfort temperature range by a maximum value of 3 ${ }^{\circ} \mathrm{C}$, and a consequent increase in the $W H D_{\mathrm{w}}$ index. Moreover, this data series presents two outliers, referred to the INS3-solutions. In particular, the INS3-WIN2 combination presents thermal discomfort indexes lower of around 51\% than the INS1-solutions, contrary to what occurs with the other shading operation.
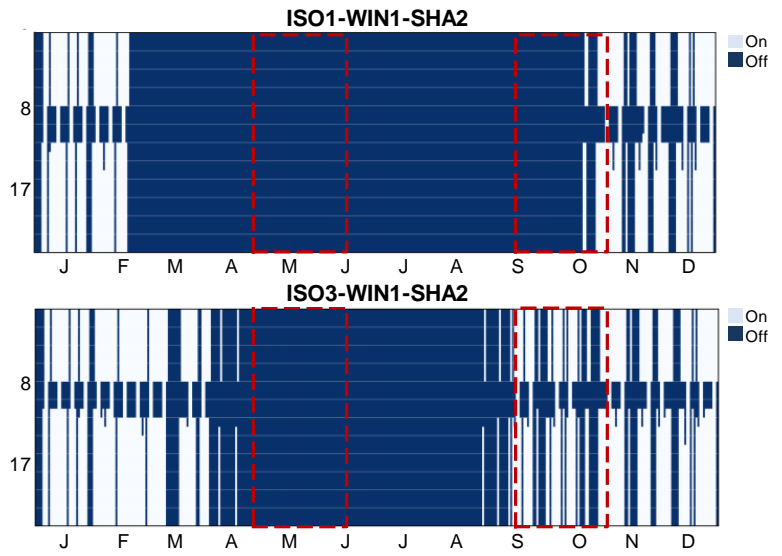

Figure 5: Annual shading activation schedule.
The design of the shading devices aimed at minimizing the glare discomfort occurrence leads to a longer activation period of the devices as the wall thickness is reduced, as shown in Figure 5; thus, since the shading devices for the INS3-WIN2 solution are switched on during the second part of the free-floating period (red dotted lines in Figure 5), they have much more influence on the thermal behaviour of the building storey than the other combinations, by decreasing the indoor operative temperatures.

Moreover, the results also show a little effect of the dimension of the window frames both on the visual and thermal performance.

In Figure 6, the results of the visual and thermal comfort analysis for each combination are shown for the Southoriented offices, as well as the overall energy performance for the entire building storey, in terms of overall non-renewable primary energy for the considered services (i.e. space heating, space cooling and lighting). A clear trend as regard the visual performance is shown in the graphs; as the $s D A_{500,50 \%}$ increases from $37 \%$ to $65 \%$, for the first (INS1-60 cm of wall thickness) to the last combination (INS3-44 cm of wall thickness) respectively, the electrical energy consumptions for lighting decreases by a $47 \%$. The counterpart of these improvements is a worsening as regard the glare conditions. Moreover, the greater negative influence of the visual comfort-based shading operation on the thermal performance with respect to the effect of the thermal comfort-based one on the visual performance, already highlighted in Figure 4, are also confirmed in terms of EP values; in fact, an increase in both heating and cooling energy consumption is underlined between the same combination of opaque and transparent solutions, implementing the two shading operation schedules $(38 \%$ and $52 \%$ for the heating and cooling consumptions respectively, for the INS1-WIN1-SHA2 solution). Despite the increase in heating and cooling consumption, the nZEB requirements are respected for all the combinations, except the INS3-solutions which show incompliances with the requirements for the energy needs for space heating, due to higher thermal transmittance values.

Among the tested combinations, an optimal solution that ensures visual comfort and acceptable thermal comfort levels can be identified. With a view to the visual comfort, it is of crucial importance to consider not only the occurrence of glare discomfort but also the daylight availability. Optimal packages of energy efficiency measures that guarantee acceptable visual comfort conditions $\left(s D A_{500,50 \%} \geq 50 \%\right.$ and $F_{D G P \text {,exceeded }} \leq 5 \%$, in red filled in Figure 6) can be identified. Since the reference technical standards for the thermal comfort evaluations (EN 16798-1) do not require any acceptable value as regard the $W H D$ indexes, it was assumed that the optimal combination is the one presenting the WHD values closest to zero; thus, the best combination that optimises both domains is the one that minimise the thermal discomfort indexes among the acceptable solutions as regard the visual comfort. This is 
characterised by the VIP-insulation, $5 \mathrm{~cm}$ thick frame and the combined shading operation. Figure 7 shows and compares the overall performances of the optimal solution together with the two solutions that optimise the thermal and the visual domains respectively. The thermal-optimal solution is characterised by the EPS external insulation, the $8 \mathrm{~cm}$ thick frame and the thermal-based shading operation, while the visualoptimal one implements the VIP-insulation, $5 \mathrm{~cm}$ thick frame and the visual-based shading operation. The radar charts are composed of 5 axes, each one designed so that the external value represents the favourable situation, while the central point the worst one. Each axis shows a different parameter $\left(E P_{\mathrm{gl}, n r e n}, W H D_{\mathrm{c}}\right.$ and $W H D_{\mathrm{w}}$ for the thermal comfort performance, and $s D A_{500,50 \%}$ and $F_{D G P \text {,exceeded }}$ for the visual comfort performance), and the axes extremes represents the limit conditions for each simulated parameter.

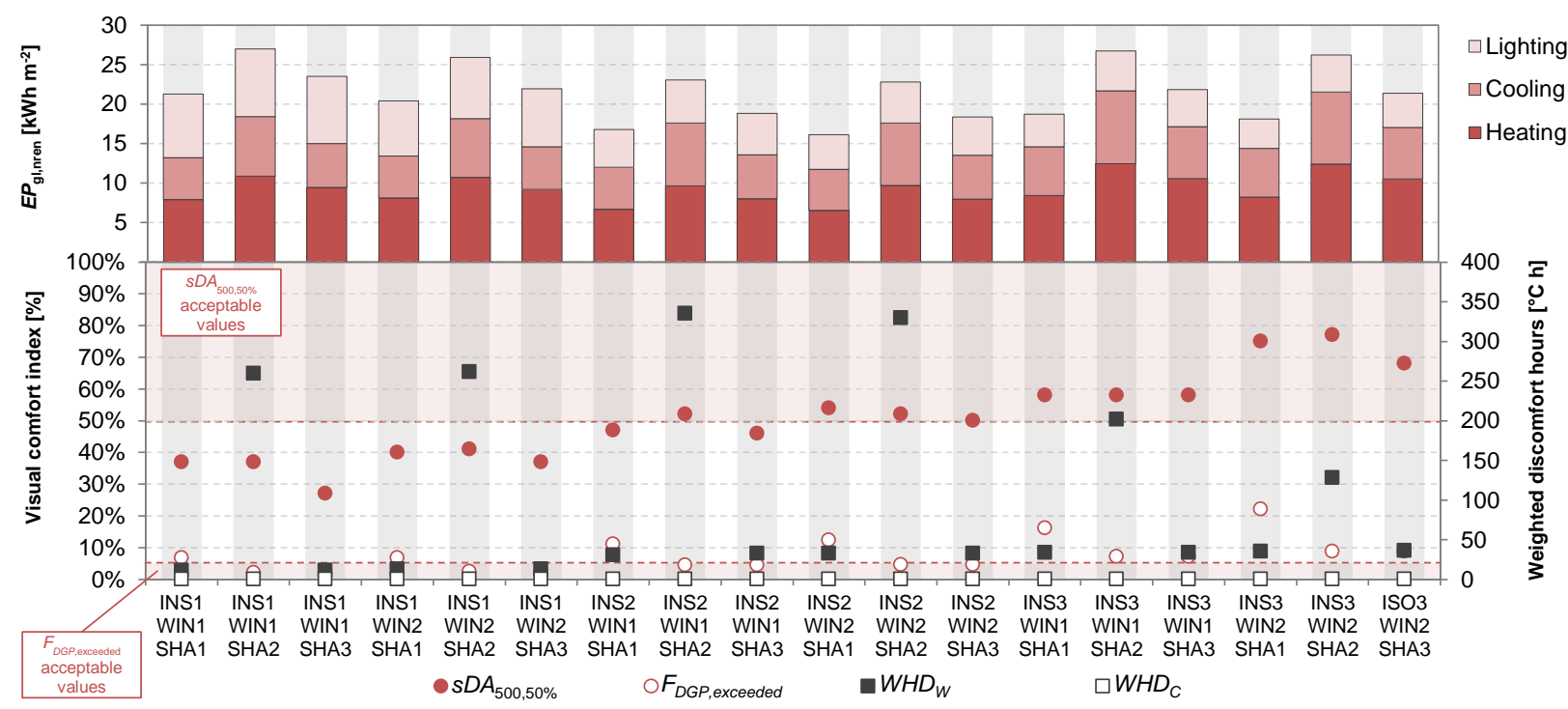

Figure 6: Results of the energy performance, visual and thermal comfort analysis.
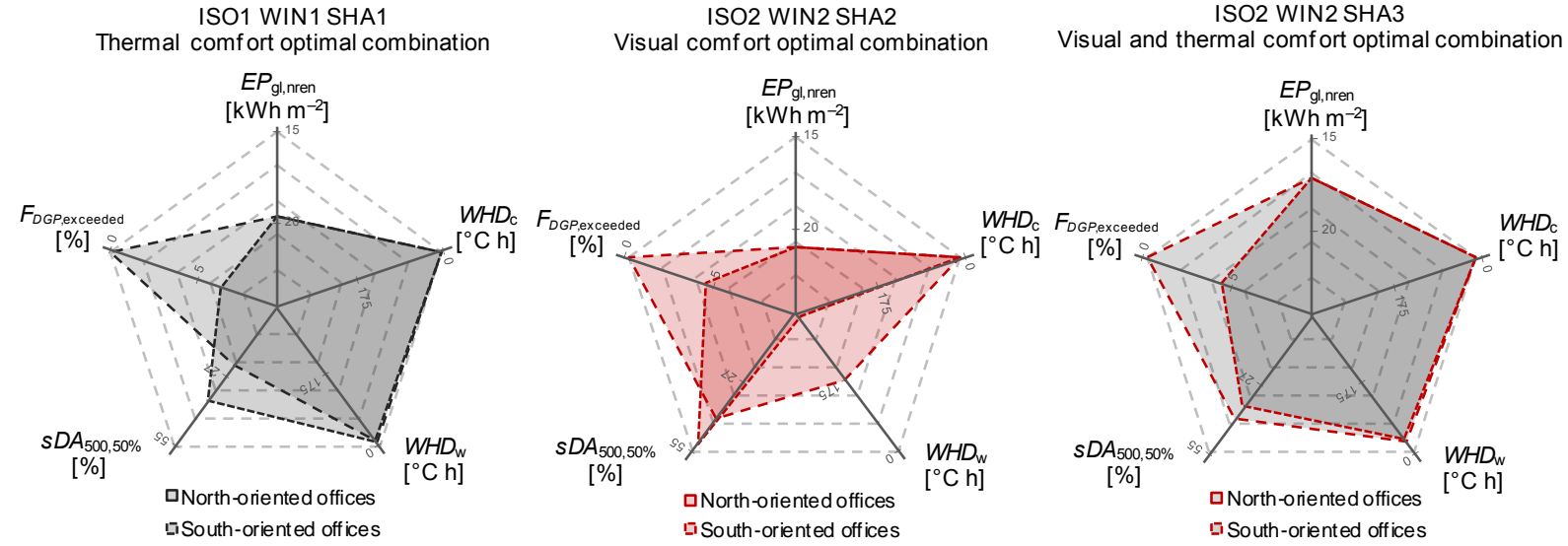

Figure 7: Comparison between the optimal combinations.

Among the three analysed combinations, the thermal comfort optimal one shows the worst visual comfort conditions as regard both the daylight availability and the glare discomfort; in the same way, the visual comfort optimal combination leads to very high values of $W H D_{\mathrm{w}}$ and overall $E P$ values due to an increase of the heating and cooling energy consumptions. Nevertheless, the optimal solution, in addition to optimizing both the thermal and visual performance, represents also one of the best solutions in improving the building energy performance.

\section{Conclusion}

The research presents an approach aimed at optimizing the overall building performance and identifying a trade- off between the indoor environmental quality and the compliance with the nZEB requirements.

Different energy efficiency solutions were tested for a representative storey of an existing office building; visual and thermal comfort and energy performance were evaluated. The main results highlight the strong influence of the solar shading devices operation on the visual and thermal performance. An imbalance between the two domains is once again highlighted when considering retrofit actions on the building envelope. Thus, other parameters affecting the thermal performance should be considered in a holistic building optimization for enhancing the best visual and thermal comfort condition. 
Nevertheless, the best solution in guaranteeing thermal, visual and energy performance resulting from this study is however characterised by not negligible costs, which may lead to an incompliance with the cost-effectiveness requirements. Downstream of a cost-optimal analysis other options could emerge, maybe in spite of a slight worsening of some of the considered comfort parameters.

Future works will be focused in analysing the effect of the proposed energy refurbishment measures on the thermal and visual performance for other building typologies and climates.

\section{Acknowledgement}

This research was carried out within the "Renovation of existing buildings in NZEB vision (nearly Zero Energy Buildings)" Project of National Interest (Progetto di Ricerca di Interesse Nazionale - PRIN) funded by the Italian Ministry of Education, Universities and Research (MIUR). The authors thank "Città Metropolitana di Torino" for having provided the data on the case study.

\section{References}

Ajajia, Y., Andréa, P. (2015). Thermal comfort and visual comfort in an office building equipped with smart electrochromic glazing: an experimental study. Energy Procedia 78, 2464-2469.

Ballarini, I., De Luca, G., Paragamyan, A., Pellegrino, A., Corrado, V. (2019). Transformation of an Office Building into a Nearly Zero Energy Building (nZEB): Implications for Thermal and Visual Comfort and Energy Performance. Energies 12, 895.

Corrado, V., Ballarini, I., De Luca, G., Primo, E. (2017). Riqualificazione energetica degli edifici pubblici esistenti: direzione nZEB. Studio dell'edificio di riferimento uso uffici della PA nella zona climatica Nord Italia (zona E: $2100<\mathrm{GG} \leq 3000$ ). Report RdS/PAR2017 (in Italian).

David, M., Donn, M., Garde, F., Lenoir, A. (2011). Assessment of the thermal and visual efficiency of solar shades. Building and Environment 46, 14891496.

Dussault, J., Gosselin, L. (2017). Office buildings with electrochromic windows: a sensitivity analysis of design parameters on energy performance, and thermal and visual comfort. Energy and Buildings $153,50-62$.

European Commission (2010). Directive 2010/31/EU of 19 May 2010 on the energy performance of buildings (recast).

European Committee for Standardization (2005). Ergonomics of the thermal environment - Analytical determination and interpretation of thermal comfort using calculation of the PMV and PPD indices and local thermal comfort criteria (EN ISO 7730).
European Committee for Standardization (2011). Light and lighting. Lighting of work places. Part 1: Indoor work places (EN 12464-1).

European Committee for Standardization (2017). Energy performance of buildings - Overarching EPB assessment - Part 1: General framework and procedures (EN ISO 52000-1).

European Committee for Standardization (2018). Daylight in Buildings (EN 17037).

European Committee for Standardization (2019). Energy performance of buildings - Part 1: Indoor environmental input parameters for design and assessment of energy performance of buildings addressing indoor air quality, thermal environment, lighting and acoustics - Module M1-6 (EN 16798-1).

Hernández, F.F., López, J.M.C., Suárez, J.M.P., Muriano, M.C.G., Rueda, S.C. (2017). Effects of louvers shading devices on visual comfort and energy demand of an office building. A case study. Energy Procedia 140, 207-216.

IES Daylight Metrics Committee (2012). IES Spatial Daylight Autonomy (sDA) and Annual Sunlight Exposure (ASE). Report LM-83-12.

Italian Republic (2015). Decreto inter-ministeriale 26 giugno 2015, Applicazione delle metodologie di calcolo delle prestazioni energetiche e definizione delle prescrizioni e dei requisiti minimi degli edifici (in Italian).

Mainini, A.G., Bonatoa, D., Polia, T., Speroni, A. (2015). Lean strategies for window retrofit of Italian office buildings: impact on energy use, thermal and visual comfort. Energy Procedia 70, 719-728.

Pellegrino, A., Cammarano, S., Lo Verso, V.R.M., Corrado, V. (2017). Impact of daylighting on total energy use in offices of varying architectural features in Italy: Results from a parametric study. Building and Environment 113, 151-162.

Reinhart, C.F. (2002). Effects of Interior Design on the Daylight Availability in Open Plan Offices. Proceedings from Summer Study of the American Commission for an Energy Efficient Environment (ACE). Pacific Grove (California, U.S.A), August 18-23 2002.

Reinhart, C.F. (2004). Lightswitch-2002: a model for manual and automated control of electric lighting and blinds. Solar Energy 77(1), 15-28.

Xue, P., Li, Q., Xie, J., Zhao, M., Liu, J. (2019). Optimization of window-to-wall ratio with sunshades in China low latitude region considering daylighting and energy saving requirements. Applied Energy 233-234, 62-70. 